The evident relationship between sunset and arrival in the roosting area and entry into the roost, suggest that both may have been determined by light intensity. However, I did not find that these events always took place earlier on overcast than on sunny evenings. I therefore conclude that light intensity plays an important but not exclusive role in their timing.

Cramp and Simmonds, who give an account of roosting in Merlins, state that before settling down for the night the birds often engage in spectacular aerial chases. These are more frequently seen near roosts used by more than one bird. ${ }^{1}$ I only saw two aerial chases.

On 19 January, two Merlins, engaged in an aerial chase, were seen 17 minutes before sunset.

Almost as soon as they came into view they were joined by a third falcon. The usual kee kee kee call was heard from at least one of the group, which was lost to view after a few seconds. At that time the hawk had not as yet arrived near the roost. Eighteen minutes before sunset on 2 February, as I was walking from home to the roost, a Merlin chasing another flew overhead. Nearer the roost a female Merlin was perched on a weeping birch in a garden. It kept up a series of calls throughout the time I was within earshot. About 2 minutes later, I arrived in the roosting area and the male Merlin was already on one of its "traditional" perches. It flew into the roosting tree 6 minutes after sunset.

' CRAMP,S. and SIMMONDS, K.E.L. 1980. Handbook of the birds of Europe, the Middle East and North Africa. Vol. 2. Oxford. 695 pp.

\section{AN UNUSUAL VISITOR}

CURTIS POLLOCK, Box 40, Hyas, Saskatchewan. SOA OLO

When Randy Krukoff of Canora arrived home around midnight on 8 March, he found an unusual visitor waiting by the door, this Eastern Screech-Owl. Although locally common in eastern Canada and the United States, it is considered quite rare in Saskatchewan where it is at the extreme northwest portion of its range. In The Birds of Canada (Godfrey, 1966; Nat. Mus. Canada, Ottawa) it is described as a"permanent resident in ... southern Saskatchewan (Yorkton; breeding range not well known, but the bird has been reported occurring west to Cypress Hills region and north to Saskatoon)." The Birds of North America states that "Eastern Screech-owls are common in a wide variety of habitats: woodlots, forests, swamps, orchards, parks, suburban gardens" (Robbins, et. al., 1983; Western Publ. Co., N.Y.). However, the Saskatchewan Natural History Society says that they prefer wooded river valleys, and society members conducted a search last April for evidence of the bird breeding in the Assiniboine and Whitesand River valleys in this area which is considered to be one of the most probable locales for the species' occurrence in this province. They were unsuccessful at that time.

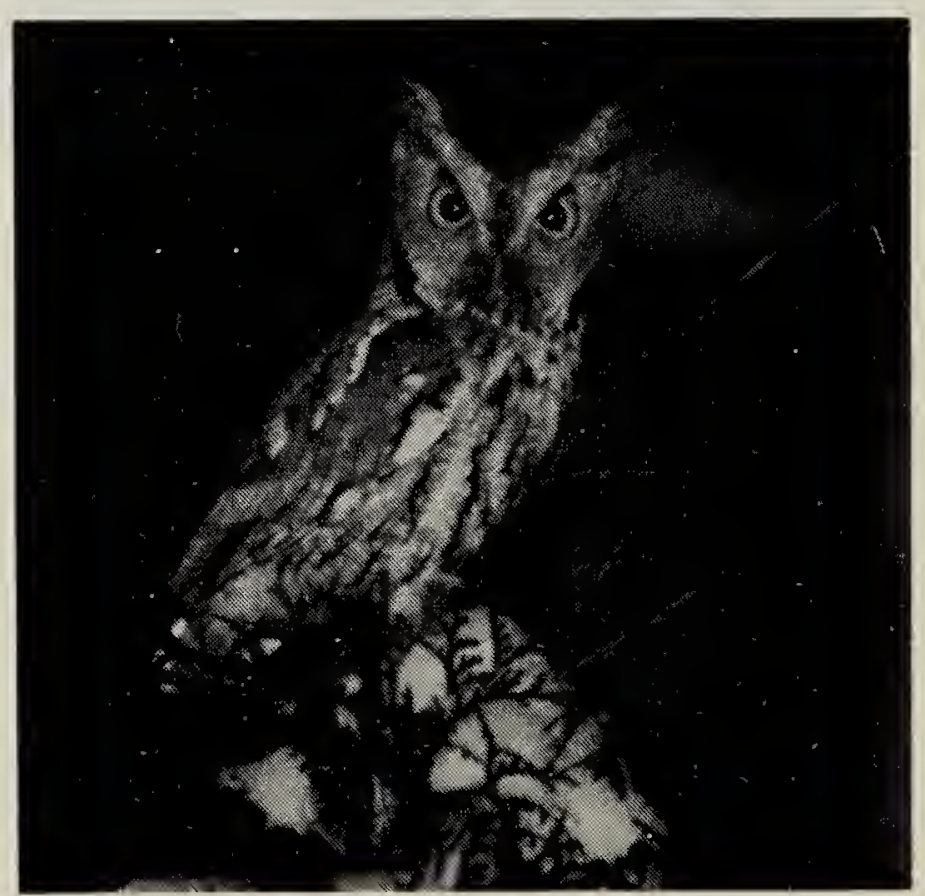

